\title{
Cellular Logic with Orthogonal Ribosomes
}

\author{
Oliver Rackham and Jason W. Chin* \\ MRC Laboratory of Molecular Biology, Hills Road, Cambridge CB2 2QH, England, UK \\ *Email:chin@mrc-lmb.cam.ac.uk
}

\begin{abstract}
Supporting Information:
1. Construction of compatible rRNA input plasmids: The RSF rRNA expression plasmid was derived from the previously described Col E1 expression plasmid (pTrc16S23S) ${ }^{1}$. The RSF1030 replicon, containing a kanamycin resistance gene, was amplified by PCR from pRSFDuet-1 (Novagen) using the oligonucleotides

5'-AACTAGGGTACCGAATTCGGGCCTCTAAACGGGTCTTGAGG-3'

and 5'-ATTGCAGCATGCCATATGGTAACGGAATAGCTGTTCGTTGAC-3’. The resulting PCR product was digested with Kpn I and $S p h$ I and used to replace the Kpn I, Sph I replicon-containing portion of pTrc16S23S ribosome plasmids. CAT activity assays for orthogonal ribosome activity were performed as previously described ${ }^{1}$.
\end{abstract}

2. Construction of logic gate plasmids: p21, a p15A origin-containing plasmid that constituitively expresses a cat-upp fusion mRNA, was used to create the logic gate plasmids. An $\omega$ allele of lacZ (M15, a deletion of amino acids $11-$ 41) was created by performing enzymatic inverse PCR on pTrcHis2/lacZ (Invitrogen), using the following oligonucleotides 5’GCGAGGAAAGGTCTCATCGTCGCCCTTCCCAACAGTTGCGCAGCCTG-3'

and 5'-CAGGGAGTAGGTCTCAACGACGTTGTAAAACGACGGGATCTATC-3'. This $\omega$ derivative of pTrcHis2/lacZ was used as a PCR template to create $\omega$ fragments containing mutant ribosome binding sites, using oligonucleotides flanking the lac $Z$ gene. $\alpha$ fragment genes with altered ribosome binding sites were created by PCR with the original $\mathrm{pTrcHis} 2 / \mathrm{lacZ}$ as a template. To generate AND logic gate plasmids the p21 backbone, and $\alpha$ fragments containing two distinct ribosome binding sites were digested and combined in a three-way ligation (replacing the cat-upp fusion gene). To generate OR logic gates one $\alpha$ fragment was replaced by an $\omega$ fragment in the ligation.

3. Measuring logic function output: The AND function was implemented in BW26444 cells, which are deleted in lacZ. Their genotype is $\left(\Delta(\right.$ araD-araB $) 567, \Delta\left(\right.$ lacA-lacZ) 519(::FRT), lacIp-4000(lac $\left.\mathrm{I}^{\mathrm{q}}\right), \lambda$, rpoS396(Am), rph-1, $\Delta(r h a D-$ $r h a B) 568, h s d R 514)$. Heat shock competent BW26444 cells containing the logic gate plasmid were prepared by standard $\mathrm{CaCl}_{2}$ treatment, and combinations of rRNA inputs accessed by double transformation. Transformed cells were recovered in SOB with $2 \%$ glucose and transferred to LB agar containing $2 \%$ glucose, $50 \mu \mathrm{gml}^{-1}$ ampicillin, $25 \mu \mathrm{gml}^{-1} \mathrm{kanamycin}$ and $12.5 \mathrm{gml}^{-1}$ tetracycline and incubated $\left(16 \mathrm{~h}, 37^{\circ} \mathrm{C}\right)$. Individual colonies were transferred to each well of a 96 well culture block containing $100 \mu \mathrm{l}$ of media (LB containing $2 \%$ glucose, $50 \mu \mathrm{gml}^{-1}$ ampicillin, $25 \mu \mathrm{gml}^{-1} \mathrm{kanamycin}$ and $12.5 \mu \mathrm{gml}{ }^{-1}$ tetracycline) and grown overnight. Cells were pelleted by centrifugation $(3000 \mathrm{~g}, 5 \mathrm{~min})$ and resuspended in $1 \mathrm{ml}$ of LB containing $50 \mathrm{\mu gml}^{-1}$ ampicillin, $25 \mathrm{ggml}^{-1}$ kanamycin, $12.5 \mu \mathrm{gml}^{-1}$ tetracycline. After a futher $1 \mathrm{~h} \mathrm{incubation}\left(37^{\circ} \mathrm{C}, 250\right.$ $\mathrm{rpm}$ ) cells were supplemented with isopropyl- $\beta$-D-thiogalactopyranoside (to $1 \mathrm{mM}$ ), and incubated $\left(37^{\circ} \mathrm{C}, 250 \mathrm{rpm}, 4 \mathrm{~h}\right.$ ) and the $\mathrm{OD}_{600}$ measured. Cells were pelleted at $3000 \mathrm{~g}$, resuspended in $100 \mu \mathrm{L}$ BugBuster HT (Novagen) and permealised by shaking for 25 minutes. An equal volume of $2 \mathrm{x}$ buffer $\mathrm{Z}\left(120 \mathrm{mM} \mathrm{Na}_{2} \mathrm{HPO}_{4}, 80 \mathrm{mM} \mathrm{NaH}_{2} \mathrm{PO}_{4}, 20 \mathrm{mM} \mathrm{KCl}, 2 \mathrm{mM} \mathrm{MgSO}\right.$, 100 $\mathrm{mM} \beta$-mercaptoethanol) containing fluorescein di- $\beta$-D-galactopyranoside (Molecular Probes, final concentration $0.5 \mathrm{mM}$ ) was added and incubated $\left(22^{\circ} \mathrm{C}\right)$ until a strong fluorescent signal was detected (approximately 5 min). Cells and debris were pelleted and the clarified supernatant transferred to a 96 well plate. Fluorescence was detected using a Spectra Max Gemini XS (Molecular Devices), with excitation at $485 \mathrm{~nm}$ and emission detection at $538 \mathrm{~nm}$.

The OR function was created in GH371 E. coli, which produce the $\omega$ fragment of $\beta$-galactosidase due to a chromosomal deletion corresponding to amino acids $11-41$ within the $l a c Z$ gene. The other experimental procedures were as described above for the AND function.

Fluorescence was normalized for cell density and time of incubation with $\beta$-galactosidase substrate, using the equation: Fluorescence $=1000 \mathrm{x}\left(\right.$ raw fluorescence $\left.{ }_{450 \mathrm{~nm}}\right) /\left(\mathrm{t} \cdot \mathrm{V} \cdot \mathrm{OD}_{600}\right)$. Where $(\mathrm{t})$ is time of incubation in seconds and $(\mathrm{V})$ is the volume of culture used.

\section{References}

(1) Rackham, O.; Chin, J. W. Nature Chem. Biol. 2005, 1, 159-166. 